\title{
Prospects of Agroforestry as Climate-smart Agricultural Strategy in Cocoa Landscapes: Perspectives of Farmers in Ghana
}

\author{
Albert A. Arhin ${ }^{1}$, Ernestina F. Antoh ${ }^{1}$, Sampson Edusah ${ }^{1} \&$ Kwaku Obeng-Okrah ${ }^{1}$ \\ ${ }^{1}$ Bureau of Integrated Rural Development (BIRD), Kwame Nkrumah University of Science and Technology, \\ Ghana \\ Correspondence: Albert A Arhin, Bureau of Integrated Rural Development (BIRD), Kwame Nkrumah University \\ of Science and Technology, University Post Office, Kumasi, Ghana. Tel: 233-555-939-173. E-mail: \\ aaarhin@knust.edu.gh
}

Received: May 18, 2019 Accepted: June 6, 2020 Online Published: December 1, 2020

doi:10.5539/sar.v10n1p20 URL: https://doi.org/10.5539/sar.v10n1p20

\begin{abstract}
Climate-Smart Agriculture (CSA) is increasingly being promoted by the international community to help farmers adapt to climate change and lift them out of poverty. An essential technique that is promoted under the climatemitigating smart agriculture policy package to reduce forest loss is agroforestry - the planting of woody plants or trees into farming systems. Integrating agroforesty into cocoa landscapes, it is argued, create forest-like habitats which serves as faunal refuges, sequester carbon and therefore contribute to increasing agricultural productivity, resilience (adaptation) and removal of greenhouse gas emissions. This article uses a qualitative data collected from 100 households in seven communities around the Kakum National Park in the Twifo Hemang Lower Denkyira District in Ghana, where a climate-smart agriculture programme is being piloted. The study analysed the extent of willingness of farmers to participate in interventions that promote increased adoption of agroforestry in cocoa landscapes. The result shows that though farmers have favourable perception about the role of agroforestry on cocoa systems, and are willing to adopt the practice, this does not automatically translate into their willingness to participate in agroforestry program that was asking them to extend the number of trees currently maintained on their cocoa landscapes. The study further reveals that size of farms, the age and height of cocoa trees, extension support and the general ecology of the cocoa varieties as some of the reasons influencing whether the agroforestry practices promoted could be adopted or not.
\end{abstract}

Keywords: climate-smart agriculture, reduicing carbon emissions, agroforestry, Ghana

\section{Introduction}

There exsits a body of scientific literature that has established that anthropogenic increase of atmospheric greenhouse gases (GHGs) is causing modifications in the Earth's climate (IPCC, 2013). Although several impacts have been projected for global climate change, agriculture remains one of the sectors where the impacts of climate likingchange are expected to be significantly affected. Climate-related crop failures, livestock deaths and fishery collapses are examples of impacts of climate change already causing economic losses and undermining food security globally. These are likely to become more severe due to projected increases in temperature, drought, extreme weather events and plant diseases as a result of climate change (Cline, 2008; Lobell et al. 2008; Boko, et al. 2007). According to Brown and Funk (2008), there are also concerns about food security, especially in regions with widespread poverty, unstable governments, and fragile agricultural systems. These challenges are likely to be exacerbated with accelerating climate change. While climate change could threaten agriculture-dependent livelihoods and economies in the foreseeable future, the sector also contributes approximately $11 \%$ of the global greenhouse gas emissions that influence climate change ome research has further established that expansion of agriculture remains the foremost cause of deforestation and degradation, which is a significant driver of carbon emissions in developing countries (Acheampong et al., 2019; Angelsen et al., 2001). To advance the role of agriculture in climate change mitigation and adaptation efforts, the concept of Climate-Smart Agriculture is increasingly being promoted by the international community. Climate-smart agriculture, it is hoped, can help farmers adapt to climate change and lift them out of poverty while at the same time mitigating the impact of human activities on climate change. A climate smart cocoa production is one where the production is expected to integrate strategies that simultaneously reduce carbon emissions, improve 
producitiviy and help farmers to adapt to climate change.

Series of research have also shown that forestand landuse change for agricultural purposes remain a significant contribution to deforestation and climate change. Cocoa production has particularly come under spotlight for its role in driving deforestation, because of expansion of farms into forest landscapes (Harris et al., 2012; Hosonuma et al., 2012). Attempts by the United Nations Framework Convention on Climate Change (UNFCCC) to reduce forest loss, have led to the introduction of the policy of REDD+ (Reducing Emissions from Deforestation and Forest Degradation and the role of conservation, sustainable management of forests and enhancement of carbon stocks). REDD+ was adopted by the UNFCCC in 2007 as a global policy to reduce forest loss from the forestry sector (UNFCCC, 2010). REDD+ also remains an essential delivery mechanism for the seventeen Sustainable Development Goals (SDGs) agreed by the 193 countries of the United Nations General Assembly in 2015 to among other things end poverty and hunger and improve global prosperity (Lima et al., 2015; Turnhout et al., 2016). In its most basic sense, REDD+ aims to provide economic incentives for tropical countries to reduce deforestation and enhance carbon stock stored in their forests. Countries that are able to reduce their deforestation and verified carbon emissions are expected to be rewarded through market-based or non-market financial schemes (Angelsen, 2008; Pistorius, 2012). Climate-smart agriculture further remains an essential delivery strategy for REDD+ for several countries.

An essential technique that is promoted under the climate-smart agriculture policy package to reduce forest loss is agroforestry, defined asthe planting of woody plants or trees into farming systems. Agroforestry can also be defined as a dynamic, ecologically based, natural resource management system that, through the integration of trees on farms and in the agricultural landscape, diversifies and sustains production for increased social, economic and environmental benefits for land users at all levels (FAO, 2015). The aim and rationale of agroforestry systems and technologies in cocoa landscapea, therefore, is to optimize positive interactions between the components involved i.e. tress/shrubs and crops and or animals, and between these components and the physical environment in order to obtain higher total, more diversified and or more sustainable production with available resources than is possible with other forms of land use under prevailing ecological and socio-economic conditions.

Other techniques encapsulated by the concept of CSA include conservation agriculture, intercropping, integrated crop-livestock management and improved water management and crop rotation. The use of agroforestry as a climate-smart agricultural strategy is particularly gaining currency in cocoa landscapes. There is the view that compared to monoculture, the diversity of polycultures is also likely to improve the resilience of agricultural systems, minimizing yield losses from weather extremes including flooding and drought. These ecological and agronomic benefits can translate into human benefits as well, with both polyculture systems and perennial crops considered important strategies within the framework of 'climate-smart agriculture' (Tom and El-Lakany). Agroforestry is considered a key strategy in climate change adaptation hence its incorporation into CSA. Some of the earlier studies indicate that agroforestry addresses food security due to the multiple cropping system that provides crop diversity, which ensures multiple produce throughout the year. Moreover, the interaction among crop components promotes nutrient cycling and other ecological services, such as erosion control. This helps improve soil condition that, in turn, improves crop or food production. Thus, continuous and sustainable promotion of agroforestry under CSA as the production technology for sustainable forest management and improved land use for maximum benefits including food security and also as a major component with potentials as part of an agroforestry system.

Despite the increasing emphasis and promotion of agroforestry as an essential component of the climate-smart agriculture approach of reducing forest loss, our understanding of its potentials and barriers from the perspectives of farmers is still limited. Research on this is critical because whether agroforestry will work or not depends on the participation of farmers in the various climate-smart agricultural programmes that are being promoted by state and non-state institutions in various communities. The aim of this paper is, therefore, to gather some perspectives about the extent to which agroforestry can be successful as a climate-smart agricultural strategy to reduce forest loss in cocoa landscapes. Specifically, the paper asks whether farmers will be willing to participate in interventions that promote increased adoption of agroforestry in cocoa landscapes. Following this introduction, the remaining sections of the paper is structured as follows. The next section reviews a literature on climate-smart agriculture, agroforestry and agricultural/cocoa production. This has been followed by the REDD+ process in Ghana and the study methodoly. The next section presents the results. The succeeding section discusses the results and tie the paper together through a conclusion. 


\subsection{Climate-smart Agriculture, Agroforestry and Agricultural/cocoa Production}

Climate-Smart Agriculture (CSA) has gained traction in recent times as an option to sustainably transform the agriculture sector. According to the Food and Agriculture Organisation (FAO, 2010: 5), CSA can be defined as "an agriculture that sustainably increases productivity, resilience (adaptation), reduces/ removes GHGs (mitigation), and enhances achievement of national food security and development goals." Advocates argue that CSA provides 'triple win' outcomes for agricultural productivity, climate change adaptation and climate mitigation and sustainable management of the environment (FAO, 2013). As such, programmes promoting CSA attempts to achieve these goals by encouraging farmers and agricultural producers to adopt wide range of practices. Agroforestry remains a leading practice that is encouraged in several climate-smart agricultural programmes. Agroforestry is a collective name for land use systems and practices in which woody perennials are deliberately integrated with crops and/or animals on the same land management unit (ICRAF, 1993). Discussions about climate change have drawn attention to the positive role that could be played by agroforestry in dealing with problems related to land-use and rising carbon emissions (Dixon, 1995; Albrecht \& Kandji, 2003; Nair et al, 2009; Minang et al, 2015). The attractiveness of an agroforestry approach to land development lies in the potential role of tress/shrubs to alleviate some of the major physical and economical constraints facing farmers and pastorials in many parts of the tropical world. According to FAO (2015), agroforestry is particularly crucial to smallholder farmers and other rural people because it can enhance their food supply, income, and health. Furthermore, agroforestry systems are multifunctional systems that can provide a wide range of economic, sociocultural, and environmental benefits (Minang et al, 2015).

Cocoa is one of the most important cash crops grown in West Africa. In Ghana, it is estimated that nearly one million small scale farmers are engaged in cocoa production as the main source of livelihoods. Cocoa cultivation typically maintains proportions of shade trees that are viewed as a sustainable land-use practice to complement biodiversity conservation (Schroth et al. 2004). Agroforestry or maintenance of diverse trees in cocoa farms further plays important roles of improving farm income and household welfare (Gockowski et al. 2006). Griffith (2000) has also argued that cocoa agroforests create forest-like habitats, which serves as faunal refuges (Griffith 2000). For example, series of research in Central and Latin America have shown that agroforestry and cocoa plantations conserve birds, ants and other wildlife that is greater than in any other anthropogenic land use systems (also see Schroth and Harvey, 2007; van Bael et al. 2007; Faria et al. 2007). Agroforestry in cocoa landscapes have further been demonstrated to sequester carbon. In this case, they help to remove carbon from the atmosphere to mitigate climate change. Agroforestry, it is argued, helps farmers to create more diverse, integrated and sustainable land-use systems. In a recent global analysis of tree cover on agricultural lands, Zomer et al (2016) argued that the total biomass of carbon on agricultural lands could be four times higher than Intergovernmental Panel on Climate Change (IPCC) default values, with trees contributing $75 \%$ of the biomass carbon. As such, agroforestry remains forefront at the various programmes and interventions being promoted under the umbrella of climate-smart agriculture to achieve the three objectives of sustainably increasing agricultural productivity; enhancing resilience (adaptation); and reducing or removing greenhouse gas emissions.

\subsection{Climate-Smart Agriculture and the REDD+ Process in Ghana}

Ghana is endowed with array of land-based natural resources such as Gold, Timber, Cocoa, Oil palm, and Shea and has a strong commitment to democratic governance. Ghana's strategic focus of promoting climate-smart agriculture and agroforestry is tied strongly to its REDD+ programme. The REDD+ process began in Ghana in 2008. REDD+ has been adopted to reverse the country's declining forest cover estimated at $1.8 \%$ per annum. Following series of policy reviews and analyses, agricultural production-particularly expansion of cocoa farms - was identified as the main cause of deforestation in the country (Forestry Commission, 2010). In view of this, the Government of Ghana is seeking to reduce forest sector carbon emissions through the promotion of climate-smart agricultural practices (Forestry Commission, 2012; 2015). The core intention of the policy approach is to increase cocoa yields and income levels of farmers without significant expansion of total land available for agriculture. Agroforestry is a significant component of the climate-smart approach that is being promoted by the Government. In 2012, seven national REDD+ pilot projects were launched. These were (i) Kakum REDD+ Demonstration Project (ii) Portal REDD+ Projects (Bedum and Ankasa) (iii) VicDoris REDD+ Pilot (iv) Permian REDD+ Project (v) IUCN Pro-poor REDD+ project (vi) KA Poku Farms REDD+ project and (vii) Cocoa Research Institute of Ghana's REDD+ Pilot Project. This paper is focused on the Kakum REDD+ Demonstration Project being implemented in partnership with the Conservation Alliance, a Non-Governmental Organisation. It is concerned with the extent to which farmers would participate in the agroforestry practices being promoted by the NGO as part of its REDD+ pilot project.

The Kakum REDD+ Demonstration Project (KRDP) builds on series of efforts implemented by the NGO, to 
improve cocoa production and poverty reduction in the Kakum landscape in the Twifo-Heman Lower Denkyira District. The operationalisation of the climate-smart agriculture strategy under the planned REDD+ had two main strategies. These were (i) training on agronomic practices and (ii) promotion of cocoa agroforestry. First, the training on agronomic practices was meant to 'enhance the understanding of farmers and their families on the need to adopt modern and best practices of cocoa production' (Conservation Alliance, 2015:5). Such training served as a solution to the farmer's limited knowledge of appropriate cocoa farming techniques. Second, agroforestry was promoted among the farmers, just as it was being promoted at the national level. In the context of the KRDP, the central strategy used by the NGO involved awareness raising and persuasive communication to encourage the farmers to retain or extend a mixture of perennial trees on their cocoa farms to increase tree cover around the Kakum park. Coupled with the training being organised, the NGO was convinced that these strategies would help in the achievement of three main objectives linked to the REDD+ project. These were to: (i) reduce an estimated six million tonnes of carbon emissions from deforestation over a twenty-year period (by 2032); (ii) improve farmers' income and resilience through improved cocoa yields and (iii) enhance carbon stock in low shade cocoa farms. But will the optimism behind the promotion of agroforestry really bring about the expected benefits of increased cocoa yields and forest loss reduction? This was the entry point of this study.

\subsection{Study Context}

The Kakum REDD+ Demonstration Project (KRDP) is located in the Twifo-Hemang-Lower Denkyira District (THLDD) in the Central Region of Ghana. The District shares boundaries with five other Districts (Figure 1): the Twifo Atti-Morkwa District (north), Cape Coast Metropolis (South), Wassa Amenfi and Wassa Mpohor Districts (West) and Assin South District (East). Ghana's recent Population and Housing Census (PHC) in 2010 showed a total population of the District as 55,132 (Ghana Statistical Service, 2015). This comprises 49.6\% males and 50.4\% females. The geographical characteristics of the district include a topography, climate, drainage, geology and vegetation that combine to provide very good conditions for agricultural production, particularly the cultivation of cocoa and palm oil. The District is drained by five major rivers of Ghana: Pra, Neuini, Surowi, Subri and Afia. The area also has an undulating topographical landscape with altitude ranging between $60-200 \mathrm{~m}$ above sea level.
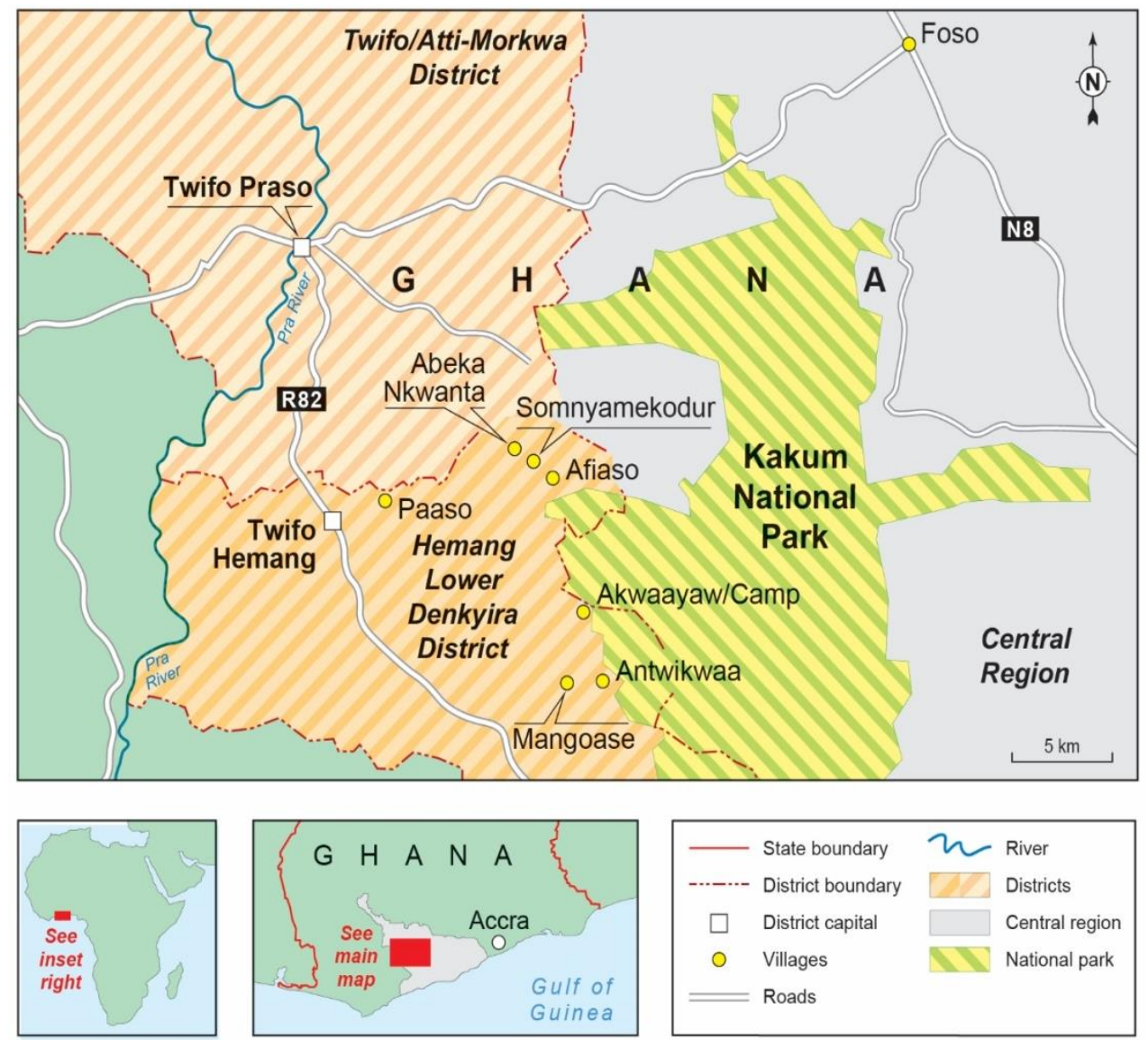

Figure 1. A map showing the study communities (study communities highlighted in yellow) 
The District lies in the semi-equatorial climate zone characterised by double maxima rainfall $(1,750 \mathrm{~mm}$ $2000 \mathrm{~mm}$ ). The study district has a bimodal rainfall pattern with the major rainy season of the District occurings between May and August while the minor rainy season occurs between August and November. The driest months run from December to March. Temperatures are fairly high in the District and range between $26^{\circ} \mathrm{C}$ and $30^{\circ} \mathrm{C}$. The coolest period occurs around August while the hottest is in March. Humidity is generally high throughout the year, ranging between $75-80 \%$ during the wet season. The District capital town of THLDD is known as Twifo-Hemang. Agriculture is the main economic activity for all the communities in the district. Small-scale agricultural processing industries including palm oil extraction, soap making and akpeteshie (local gin) distilling were also common in the communities studied. In the project communities, cocoa cultivation (alongside palm oil and citrus), was practised by the majority (90\%) of the research participants (90\%). In addition to cocoa, farmers grew some vegetables including maize, legumes, plantain, cassava and vegetables.

\section{Method}

\subsection{Study Design}

This paper is part of a broader study that is examining the extent to which climate change mitigation ideas is being translated and operationalised in Ghana. This present paper is an exploratory study and used a qualitative research methodology. This is because the main intention was to explore the perspectives and subjective views of farmers on the extent to which farmers would participate in agroforestry programmes as a climate-smart agricultural strategy. Qualitative research is characterised by its focus on understanding some aspect of social life, rather than to prove a hypothesis. Its methods generate words, rather than numbers, as data for analysis (Patton and Cochran, 2002; Bernard, 2012). As is common with a qualitative approach, the research process was more inductive than deductive (Kitchin and Tate 2000; Blaikie, 2009; Schwartz-Shea and Yanow, 2013).

\subsection{Selection of Respondents}

In selecting participants for this research, the research took notice of the fact that 'a "gold standard" that will calculate the number of people to interview is lacking' in qualitative research (Luborsky and Rubinstein, 1995: 104; also see Morse 1994). The study further noted that there is an extremely large variation in the number of participants that is considered enough for qualitative research (Burmeister and Aitken, 2012). Dworkin (2013) for instance has recommended 5 to 50 participants as an adequate number. Given this debate, the study approach was to interview as many people as possible until data saturation was reached, as is common practice in many qualitative studies (see Mason, 2010). Data saturation is reached when the data collection process no longer offers any new or additional relevant data (Guest et al., 2006; Mason 2010; Fusch and Ness, 2015). Following Fusch and Ness (2015), the approach adopted for the study to ensure data saturation involved using multiple methods to collect the data, asking multiple participants the same set of questions but in various ways and going beyond participants provided access to by gate-keepers.

The study was further guided by the suggestion that 'probability sampling techniques cannot be used for qualitative research' (Luborsky and Rubinstein, 1995: 104; also see Depoy and Gitlin 1993; Miles and Huberman 1994; Morse 1994). As such a combination of non-probabilistic sampling techniques shaped the selection of the participants for the research. These included purposive sampling, snowballing and convenience sampling. In purposive sampling, participants are intentionally selected to represent predefined categories or conditions (Miles and Huberman 1994; Luborsky and Rubinstein, 1995; Cresswell, 2007). Thus, the study focused purposively on cocoa farmers as the main source of participants. Snowballing techniques was also employed where some farmers recommended others they knew who were approached to participate in the research (Miles and Huberman, 1994). In the case of convenience sampling, the researchers used an open recruitment method where available participants were selected on a first-come, first-served basis (Luborsky and Rubinstein, 1995).

\subsection{Methods of Collecting Data}

This study was part of a larger research examining how climate change policies were being implemented to address deforestation in Ghana. In-depth semi-structured interviews, key informant interviews, focus group discussions and informal conversations were the main methods employed to collect the data. Semi-structured interviews have been argued to be highly suitable for exploring opinions, experiences and perceptions of research respondents (Rubin and Rubin, 2012; Patton, 2002). One hundred (100) semi-structured interviews were held with farmers across seven cocoa growing communities. These were Afiaso, Antwikwaa, Somnyamekodur, Paaso, Mangoase and Akwaayaw/Camp and Abeka-Nkwanta (see fig. 1). All participants provided informed consent. A topic guide or checklist containing questions about the research objectives were developed to guide the structure of the interviews. Here, the checklist contained two broad parts. The first 
contained open-ended conversations on knowledge of REDD+, perceptions of the role of agroforestry as a climate-smart agricultural strategy. The second part contained structured questions about the demographic and socio-economic characteristics of the research participants including their ages, educational level, duration lived in the respective communities and occupation. The second part also contained Likert-scale type of questions asking about the extent to which respondents agreed or not with a number of statements that had been developed from the document analysis. The interviews were mostly conducted in conversational and dialogue forms rather than as a list of questions. The dialogic approach allowed for discussion of various themes in greater depth than would have been achieved with structured questionnaires alone. Six focus group discussions were further held as part of the study. Focus groups bring together several participants to discuss a topic of interest to the researcher. It offers an encouraging social setting for exploring specific topics in depth (Mikkelsen, 2005). The method was particularly useful for exploring people's knowledge and experiences about cocoa farming practices, agroforestry and their role in promoting cocoa production and mitigating climate change impacts. The study also employed informal conversations as part of the data collection methods. Informal interviews involve some casual discussions on wide range of issues (Creswell, 2007). The informal interviews were an essential part of gaining an understanding of a setting and its members' ways of seeing particular issues or topics of interests.

\subsection{Data Analysis}

The data collected were analysed using a framework approach which facilitates rigorous and transparent analysis. The transcripts were read to identify emerging themes; a coding framework was developed based on these themes and all transcripts were coded with this framework; charts were created for all themes; these charts were used to describe similar and divergent perceptions, develop explanations and find associations between them.

The data processing and analysis followed three broad steps: (i) entry of structured data (ii) familiarisation of qualitative data and (iii) coding to organise themes, categories and patterns. This avoided the danger of 'forcing the data' to fit preconceived ideas and 'a neglect of relevant concepts and hypotheses that may emerge' (Glaser and Strauss, 2008: 34). First, the basic information of respondents and responses to the Likert scale/structured questions were entered into a Statistical Software Package, SPSS, to generate descriptive statistics about the respondents including number, age, sex and other characteristics. In the second stage, the audio files of the interviews and focus groups were transcribed. Next, the transcribed interviews and field notes were subjected to rounds of close reading and further rounds of active listening to each of the audio files. The intention here was to enable familiarisation of the stories and conversations shared by the research participants. Such a close familiarisation with, or immersion into the data collected has been recommended by researchers such as Bryman (2001), Creswell (2007) and Patton (2002). After this stage of familiarisation, at least three further rounds of listening of audio recordings and reading of transcribed scripts and field notes were carried out noting prevalent and interesting themes that would form the basis for the third stage of the data analysis: coding.

Two levels of coding were carried out. In the initial coding process, descriptive and attribute information were assigned to sections of the transcripts using pen, highlighters and other markers. In the second stage, an axial coding process was carried out to re-organise and categorise similar or related codes into themes about similar and divergent perceptions shared by the respondents. Thematic analysis has been described as the most useful method for "capturing the complexities of meaning within a textual data set" (Braun and Clarke, 2004) and we found it well suited to the analysis of the qualitative data collected. This process also helped in compiling series of quotations to illustrate the themes and the patterns that emerged from the study.

\section{Results}

\subsection{Socio-Economic and Demographic Characteristics of Respondents}

A little over half $(51 \%)$ of the research participants were between the ages of 41 and 60 . This is followed by those between the ages of 21-40 (35\%) and those over 60 years (15\%). In terms of gender, there were more males $(63 \%)$ than females $(37 \%)$. This was expected as the members of the households that usually offered to respond to the interviews were mostly men. In addressing this bias, the limited number of women was compensated through series of focus group discussions that exclusively focused on women. 
Table 1. Socio-economic characteristics of respondents

\begin{tabular}{ll}
\hline Sex of respondents & $\mathrm{N}(\%)$ \\
\hline Male & $63(63.0)$ \\
Female & $37(37.0)$ \\
Age & \\
Less than 20 years & $2(2.0)$ \\
21-40 years & $32(32.0)$ \\
41-60 years & $51(51.0)$ \\
More than 60 years & $18(18.0)$ \\
Residential status & \\
Migrant & $82(82.0)$ \\
Indigene & $18(18.0)$ \\
Level of education & \\
No formal education & $24(24.0)$ \\
Basic education & $67(67.0)$ \\
Secondary education & $5(5.0)$ \\
Tertiary & $4(4.0)$ \\
\hline &
\end{tabular}

Analysis of the educational status of the respondents showed that $24 \%$ of the respondents had no formal education. For those who have formal education, sixty-seven percent (67\%) have had basic education as the highest level of qualification, 5\% possessed secondary education while four percent (4\%) have acquired tertiary education. Eighty-two (82\%) of the respondents associated themselves as migrants while the remaining $18 \%$ described themselves as indigenes (Twifo ethnic group).

\subsection{Knowledge and Awareness of Agroforestry}

Almost all the respondents (100 respondents) showed a particularly favourable perception about the role of agroforestry in cocoa production. Members of the communities further showed increased awareness of multiple benefits of agroforestry in cocoa systems. Analysis of the data from the study showed that significant number of research participants ( 82 out of 100) were willing to plant and integrate trees into their cocoa production systems because of several benefits. These benefits could be broadly categorised into three: (i) local/personal benefits (ii) farm-supportive benefits and (iii) global/microclimate benefits (See fig. 2).

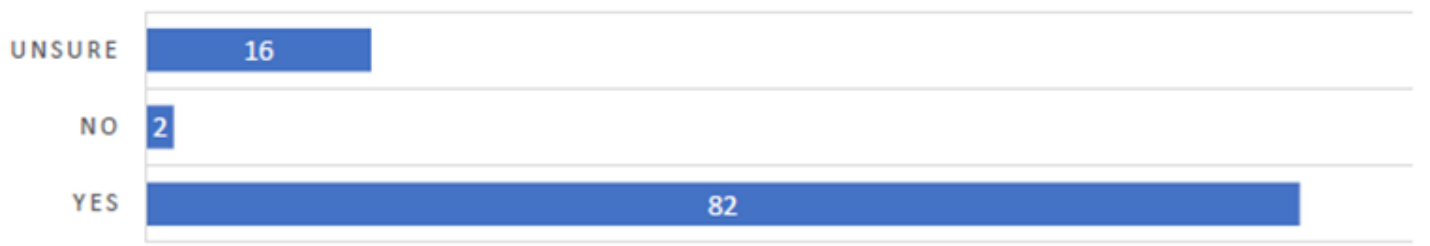

Figure 2. Would You be Willing to adopt agroforestry practices in your cocoa farms?

Source: Field study, 2014

\subsubsection{Local/personal Benefits}

These benefits serve as incentives for intense practicing of agroforestry. Research participants explained that they were willing to practice in agroforestry because of the direct benefits it provides to the farmer. The interviews and focus group discussions further revealed that the practice of agroforestry took two forms. In the first instance, farmers carefully retained some trees as part of the farming systems when local knowledge and perceptions on their impact on cocoa productivity was not negative. In the second instance, farmers practiced agroforestry by deliberately planting other crops (e.g. citrus) and trees into their cocoa farms due to advice from extension officers and other actors such as the NGO studied. According to the research participants, retaining mix of trees into the cocoa farms serves risk aversion purposes for the farmer as it enables additional income to be obtained through sales of fuelwood. As a respondent emphasised, 'our economic activity is seasonal in nature. To be honest, life is hard after the cocoa harvesting season. One of the ways through which I try to overcome the situation is to cut some branches of the trees to sell to make a living' (Cocoa farmer, Mangoase). This was corroborated by another farmer who narrated that 'the trees we plant do not just support the soil, but it also enables us to earn some additional coins when we cut and sell the branches (Cocoa farmer, Afeaso). Thus, 
agroforestry is seen as an important source of additional income for the farmers and as a strategy for maintaining resilience due to the shocks posed by the lean season.

\subsubsection{Farm-supportive Benefits}

Interviews further showed that farmers were generally willing to integrate and retain number of trees into their cocoa farms because agroforestry further provides supportive environment for cocoa trees to thrive. Farmers views about the farm-supportive role of agroforestry as a climate-smart agricultural strategy is encapsulated in the experience shared by one research participant at Somnyamekodur: 'I plant about 6 trees to each acre of my farm. When the cocoa trees are young, the planted trees help to reduce the impact of sunlight on the plantation. So, these trees help the cocoa to grow well' (Cocoa farmer (KSO 16), Somnyamekodur). Another respondent further highlighted that 'the trees we plant also help in the maintenance of the soil. Until recently, the use of chemical fertilisers was less common. It has been the trees that cool the soil and support it to perform its functions' (Interviews, Cocoa farmer (KPA 22), Paaso). It is gleaned from the two quotes above that the commonly explanations of the farm-supportive benefits of agroforestry mentioned by these research participants were provision of shade to cocoa and maintenance of soil fertility.

\subsubsection{Global/microclimate Benefits}

Still other farmers emphasised the global benefits of agroforestry as the reason they retained or introduced mix of trees on their farms. These global or extra-local benefits were expressed through expressions related to improved rainfall patterns, biodiversity conservation and carbon sequestration. As a participant emphasised in a focus group discussion at Antwikwaa, 'when the last tree dies, the last man will also die. We know that the trees protect us from ozone layer, it gives us fresh air and helps us get regular rainfall' (Farmer, Focus Group Discussion, Antwikwaa). Another farmer further shared the view that 'we experience rainfall almost every month which helps our crops to grow well. This is something which is not experienced in many of parts of the country. Do you know why? It is because the trees we grow on the farms complement the forest around us to cause the rainfall to come regularly' (Interview with farmer (KAN 14), Antwikwaa). These reflective quotes, as expressed by many of the research participants, confirm Altieri's (2004) observation that farmers are environmentally knowledgeable in terms of importance of trees. From the interviews and field observations, some of the trees that were mentioned included terminalia ivorensis (emeri), ricinodendron heudelotii (wawa), terminalia superba (ofram), ceiba pentandra (onyina), milicia excels (odum), alstonia boonei (nyamedua) and citrus such as orange.

\subsection{Views and Perceptions about the Potentials of Agroforestry to Reduce Forest Loss}

Findings from the study also showed that although farmers possess considerable knowledge and awareness about the importance of agroforestry, adoption of the practice as a climate-smart agricultural practice will not be straight forward. When respondents were asked about whether they would participate in the agroforestry component of the REDD+ programme being implemented by the organisation, only twenty percent of the research participants provided an affirmative response. Two (2) percent provided a negative response while as many as $78 \%$ of respondents were unsure whether they would be able to fully participate in the programme to plant trees that would be allowed to stand on their farms for over 15 years (see fig 3 ).

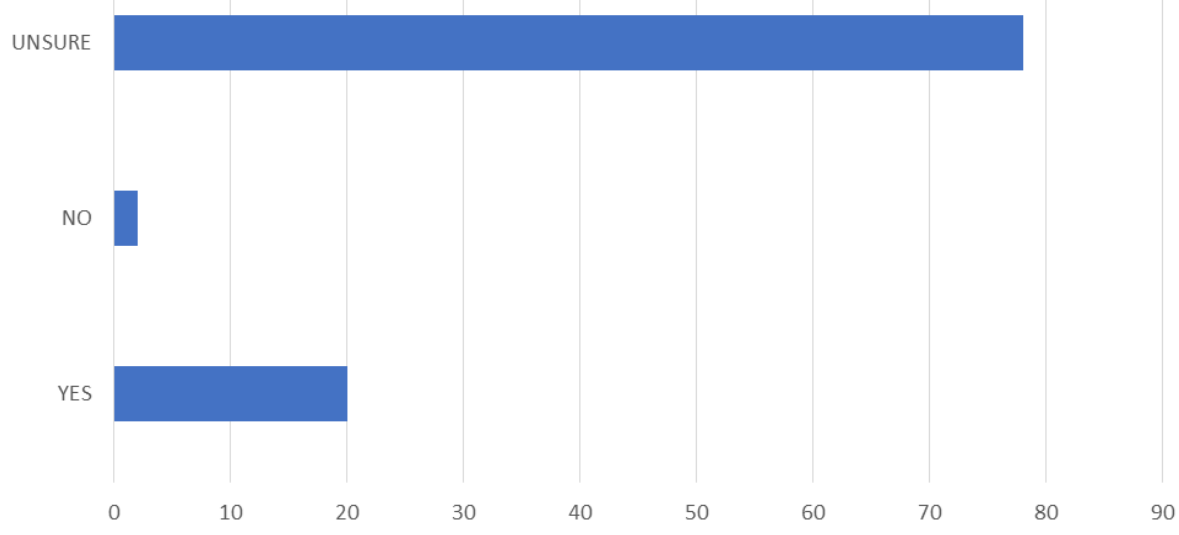

Figure 3. Would You Participate in the Redd+ Pilot Project If It Asks You to Extend the Number of Trees/Woody Plants on Your Cocoa Farms?

Source: Field study, 2014 
Discussions about the ambivalence and the reasons why the farmers were unsure or unwilling to participate in the agroforestry programme being promoted by the organisation revealed some barriers which could limit the practice of agroforestry as a climate-smart agricultural strategy on cocoa farms. These barriers have been categorised into farm characteristics (e.g. size of cocoa, height and age of cocoa farms, the general ecology of the cocoa varieties that are grown) and farmer characteristics (e.g. household size, income levels, plots of cocoa lands owned, farm maintenance culture, farmers experience, access to credit and extent and timing of application of agro-chemicals).

\subsubsection{Farm Characteristics}

Analysis of the interviews from the farmers revealed that farm characteristics related to the size, height and age of cocoa farms as well as the general ecology of the cocoa varieties that are grown by the farmers could present significant barriers to the adoption of agroforestry as a climate-smart agricultural strategy. Farmers argued that the size, height and age of cocoa farms have significant influence on the quantity of trees that may be grown and how long such trees would be allowed to stand on particular farms. From the perspectives of farmers, trees are best inter-planted into cocoa farms during their earlier years. As such farmers that have relatively aged or well-established farms may not be able to meaningfully participate in any programme that attempt to use agroforestry as a means for raising productivity, income levels and reduction of greenhouse emissions. As noted by a respondent, 'I cannot plant or retain anymore trees because I do not have any younger cocoa farm. My farms are all tall now. I have established them for nearly ten years. Growing trees in all of the farms at their prevailing heights may not be advisable' (Interview with cocoa farmer (KAC-7), Akwaayaw/Camp).

Further discussions with the farmers showed that the general ecology of the variety of cocoa cultivated across the country represents another barrier that may affect large-scale adoption of agroforestry in cocoa landscapes. Farmers expressed concerns that the hybrid cocoa varieties that are promoted by state institutions and are common across the whole country do torelate too much shade snd therefore many trees on farms. By this practice, the interviews showed that willingness of farmers to retain trees were generally high at the initial stages of their cocoa production, but the enthusiasm waned at later stages of the cocoa production. For example, although $82 \%$ of respondents were very willing to integrate, plant or retain shade trees when 'cocoa farms are young and growing' (Interview with cocoa farmer (KAF17), Afiaso), some 78\% of the respondents were unsure whether they would be able to continue to allow more trees to stand on their farms for over 15 years. This is because 'for matured cocoa farms, leaving many trees on the farms for long time is not advisable' (Interview with farmer (KSO9), Somnyamekodur). Responses from the interviews further showed that leaving too many trees on matured farms could affect cocoa productivity through diseases such as black pod and swollen shoot diseases - two of the deadliest diseases affecting cocoa production in Ghana. As noted by one farmer: 'pests and diseases-causing organisms hide and spread through shade trees to the farms' (Interview with cocoa farmer (KAF16), Afiaso). Black pod can completely destroy all yields in a particular season and swollen shoot disease decreases yield within the first year of infection, and usually kills the tree within a few years (Hill. 1973; Ameyaw et al., 2014; Domfeh et al., 2011). Thus, beyond training and awareness raising, farmers would take into consideration other factors before they would commit into practicing agroforestry as a climate-smart agricultural strategy.

\subsubsection{Farmer Socio-economic Characteristics}

Responses gathered further showed that socio-economic characteristics such as the age, residency status, social position and wealth of farmers may create barriers for the adoption of agroforestry as a climate-smart agricultural strategy. A number of farmers argued that though they were aware of the importance of agroforestry, their ages would not allow them to practice it intensively over the coming years. In Afiaso for example, an elderly man explained that 'I do not have much strength as before because of my age. I do not think I can plant or retain more trees as it may compete with my time' (Interview with farmer (KAF 6), Afiaso). In Paaso, a respondent further added that, 'at my age, I would not be able to integrate more trees into my cocoa farms. This is because a lot of time and attention is required. Besides, I do not think I will be alive in the next ten to fifteen years to bother so much about growing more trees in the cocoa farms' (Interview with cocoa farms (KPA 3), Paaso). In addition to age, social position and wealth also emerged as factors that could create incentive or barrier for the adoption of agroforestry as a climate-smart agricultural strategy in cocoa landscape. The residential status of farmers - whether indigenes or migrants also appeared as a farmer characteristic that could affect the adoption of agroforestry as a climate-smart agricultural strategy in cocoa landscapes. The interviews gathered that migrants were likely to find it difficult getting land for cocoa production or faced restrictions on the type of landuse practices they could employ on farms. 


\subsection{Discussion and Implications}

Climate-smart agriculture is increasingly becoming a cardinal strategy in the present discussions about the need to reduce forest loss to mitigate climate change. This study explored farmers views about their willingness to participate in a climate-smart strategy programme to adopt agroforestry practices to reduce forest loss and increase cocoa yields. Results from the study showed that, communities possess increased awareness of the multiple benefits of intercropping trees in cocoa systems. This compares favourably with studies by Altieri (2004) and Sonwa (2013). The training of the NGO might have influenced this awareness. However, the role of social networks and inter-generational local farming practices as other factors could also be determining factors. The research has further demonstrated that the NGO was drawing on a naïve assumption that simply raising awareness about importance of cocoa agroforestry would serve as a strong incentive for farmers to adopt the agroforestry practices to increase tree cover and to mitigate climate change. This assumption was naïve because of the biophysical and socio-economic conditions that shape the willingness of participation of the farmers in the programme. What this finding shows is that not everyone who expressed awareness of importance of agroforestry has practised it or intends to adopt it to the scale expected by the NGO.

Available research has shown that direct economic benefits from agroforestry remains a significant factor in determining its adoption potential. For example, Ayuk (1997) has demonstrated through a study in Burkina Faso that the profitability of the technology enhances the likelihood of adoption. Ndayambaje et al. (2012) have further added how the number of salaried members of the households, the gender of the head of the household, the number of meals per day, the amount of on-farm fuelwood and the geographical geographical location of the households all influence tree planting on farms. The present research has added to this body of knowledge by highlighting some of the farm, farmer and technology characteristics that equally influence willingness of farmers to participate in an agroforestry programme.

Some existing studies have further shown that agroforestry practices often fail to be taken up by small-scale farmers who are usually poor because their main priority is mostly on food and are unable to afford taking risks by investing time and labour in new technologies which have uncertain benefits in the long term (Jerneck and Olsson, 2014). This study extends our understanding that the reasons for adoption or not of agroforestry goes beyond just poverty. Similar to the findings of Meizer et al (2014), the farm, farmer and technology characteristics identified in the study combine to shape decisions of farmers to participate in agroforestry programmes.

The research raises several policy implications for the global and national discussions on agroforestry and climate-smart agriculture. First, this paper has shown that knowledge and awareness of importance of agroforestry alone would not be sufficient for farmers to adopt agroforestry practices to reduce forest loss. A number of contextual factors including the size of farms, the age and height of cocoa trees, extension support and the general ecology of the cocoa varieties influence whether the agroforestry promoted could be adopted or not. Even for many farmers who were willing to plant, retain and nurture shade trees on farms, the long-term sustainability of the shaded trees on farms remained quite in doubt for reasons such as perception of possible spread of disease stemming from too many trees on farms. Second, and a related implication is that farmers had ambivalence related to participation in programmes aimed to encourage them to adopt agroforestry in their cocoa systems. By this implication, the role of agroforestry as a climate-smart agricultural strategy to reduce deforestation could be overestimated. This draws attention to a renewed approach for the various actors championing agroforestry to address some of the barriers to adoption identified in the study.

\subsection{Conclusion and Recommendations}

The aim of this paper was to explore farmers' views about their willingness to participate in a climate-smart strategy programme related to adopting agroforestry practices to reduce forest loss and increase cocoa yields. The conclusion that can be drawn from the research is that the present optimism behind the role of agroforestry to achieve the ideals of CSA needs to be tempered. This is because though farmers may favourable perception about the role of agroforestry, and are willing to adopt the practice, this does not automatically translate into their participation in externally driven programmes on same. Future works need to engage more on understanding context-specific critical factors that would shape participation and adoption of the agroforestry practices to achieve the objectives of climate-smart agriculture. Given that farmers are already knowledgeable about the importance of agroforestry in cocoa landscapes, it is recommended to the Government and organisations promoting the practice to include well-packaged incentives and regular technical assistance to increase participation and adoption. 


\section{References}

Acheampong, E. O., Macgregor, C. J., Sloan, S., \& Sayer, J. (2019). Deforestation is driven by agricultural expansion in Ghana's forest reserves. Scientific African, 5, e00146. https://doi.org/10.1016/j.sciaf.2019.e00146

Angelsen, A., \& Kaimowitz, D. (Eds.). (2001). Agricultural technologies and tropical deforestation. CABi. https://doi.org/10.1079/9780851994512.0000

Bernard, R. H. (2012). Social research methods: Qualitative and quantitative approaches (2nd ed.). Thousand Oaks, CA: Sage.

Blaikie, N. (2009). Designing Social Research. Cambridge: Polity Press

Bryman, A. (2001). Social research methods. Oxford university press.

Bryman, A. (2008). Social research methods (3rd ed.). Oxford university press.

Burmeister, E., \& Aitken, L. M. (2012). Sample size: How many is enough? Australian Critical Care, 25(4), 271-274. https://doi.org/10.1016/j.aucc.2012.07.002

Charmaz, K. (1985). Syllabi Set for Courses in Medical Sociology.

Chernoff, J. M. (2005). Exchange is Not Robbery: More Stories of an African Bar Girl. Chicago: University of Chicago Press. https://doi.org/10.7208/chicago/9780226074795.001.0001

Cline, W. R. (2008). Global warming and agriculture. Finance and Development, 45(1), 23.

Dworkin, S. L. (2012). Sample size policy for qualitative studies using in-depth interviews. Archives of sexual behaviour, 41(6), 1319-1320. https://doi.org/10.1007/s10508-012-0016-6

Fusch, P. I., \& Ness, L. R. (2015). Are we there yet? Data saturation in qualitative research. The Qualitative Report, 20(9), 1408-1416.

Ghana Statistical Service. (2015). Poverty Maps. Retrieved from http://www.statsghana.gov.gh/docfiles/publications/POVERTY\%20MAP\%20FOR\%20GHANA-05102015. pdf

Glaser, B. G., \& Strauss, A. L. (2008). The discovery of grounded theory: strategies for qualitative research. Aldine Transaction: New Brunswick and London.

Guest, G., Bunce, A., \& Johnson, L. (2006). How many interviews are enough? An experiment with data saturation and variability. Field Methods, 18(1), 59-82. https://doi.org/10.1177/1525822X05279903

Hill, M. O. (1973). Diversity and evenness: a unifying notation and its consequences. Ecology, 54(2), 427-432. https://doi.org/10.2307/1934352

IPCC. (2013). 5th Assessment report: Climate change 2011. Geneva: Author.

Lobell, D. B., Burke, M. B., Tebaldi, C., Mastrandrea, M. D., Falcon, W. P., \& Naylor, R. L. (2008). Prioritizing climate change adaptation needs for food security in 2030. Science, 319(5863), 607-610. https://doi.org/10.1126/science.1152339

Luborsky, M. R., \& Rubinstein, R. L. (1995). Sampling in qualitative research rationale, issues, and methods. Research on aging, 17(1), 89-113. https://doi.org/10.1177/0164027595171005

Mason, M. (2010). Sample size and saturation in $\mathrm{PhD}$ studies using qualitative interviews. Forum qualitative Sozialforschung/Forum: qualitative social research, 11(3), 1-19.

Mikkelsen, B. (2005). Methods for development work and research: a new guide for practitioners. New Delhi, SAGE Publications Pvt. Limited.

Miles, M. B., \& Huberman, A. M. (1994). Qualitative data analysis: A sourcebook. Beverly Hills: Sage Publications.

Morse, R. A. (1994). Rearing queen honey bees (2 ed.). Wicwas Press.

Obeng-Odoom, F., \& Ameyaw, S. (2014). A new informal economy in Africa: The case of Ghana. African Journal of Science, Technology, Innovation and Development, 6(3), 223-230. https://doi.org/10.1080/20421338.2014.940172

Palm, C., Tomich, T., Van Noordwijk, M., Vosti, S., Gockowski, J., Alegre, J., \& Verchot, L. (2004). Mitigating GHG emissions in the humid tropics: case studies from the Alternatives to Slash-and-Burn Program (ASB). 
Environment, Development and Sustainability, 6(1-2), 145-162. https://doi.org/10.1023/B:ENVI.0000003634.50442.ca

Patton, M. Q. (2002). Two decades of developments in qualitative inquiry a personal, experiential perspective. Qualitative social work, 1(3), 261-283. https://doi.org/10.1177/1473325002001003636

Patton, M. Q., \& Cochran, M. (2002). A guide to using qualitative research methodology. Medecins Sans Frontiers.

Pistorius, T. (2012). From RED to REDD+: the evolution of a forest-based mitigation approach for developing countries. Current Opinion in Environmental Sustainability, 4(6), 638-645. https://doi.org/10.1016/j.cosust.2012.07.002

Rubin, H. J., \& Rubin, I. S. (2012). Qualitative interviewing: The art of hearing data (3rd ed.). Thousand Oaks: Sage.

Scott, K. R., Adesioye, S., Ayuk, P. B., Edafiogho, I. O., John, D., Kodwin, P., ... Nicholson, J. M. (1994). Synthesis and evaluation of amino analogues of valproic acid. Pharmaceutical research, 11(4), 571-574. https://doi.org/10.1023/A:1018978918921

Turnhout, E., Gupta, A., Weatherley-Singh, J., Vijge, M. J., De Koning, J., Visseren-Hamakers, I. J., ... Lederer, M. (2017). Envisioning REDD+ in a post-Paris era: between evolving expectations and current practice. Wiley Interdisciplinary Reviews: Climate Change, 8(1). https://doi.org/10.1002/wcc.425

Wertz-Kanounnikoff, S., Verchot, L. V., Kanninen, M., \& Murdiyarso, D. (2008). How can we monitor, report and verify carbon emissions from forests?. In A. Angelsen (Ed.), Moving Ahead with REDD: Issues, Options and Implications. Center for International Forestry Research (CIFOR), Bogor, Indonesia.

Young, A. (1997). Agroforestry for soil management (2 ed.). CAB international.

Zomer, R. J., Neufeldt, H., Xu, J., Ahrends, A., Bossio, D., Trabucco, A., \& Wang, M. (2016). Global Tree Cover and Biomass Carbon on Agricultural Land: The contribution of agroforestry to global and national carbon budgets. Scientific reports, 6, 29987. https://doi.org/10.1038/srep29987

\section{Copyrights}

Copyright for this article is retained by the author(s), with first publication rights granted to the journal.

This is an open-access article distributed under the terms and conditions of the Creative Commons Attribution license (http://creativecommons.org/licenses/by/3.0/). 